\title{
Hydrocortisone-Evoked Molecular Conversion of Alkaline Phosphatase in Suckling Rat Small Intestine
}

\author{
Yosuke TOJYO*, Kooichi SAIDA and Akitoshi SUZUKI \\ Department of Pharmacology, Niigata University School of Dentistry. \\ Niigata 951, Japan \\ Accepted June 11, 1985
}

\begin{abstract}
Suckling rats were injected with hydrocortisone at 12 and 13 days after birth and were sacrificed for the experiment at 15 days. Alkaline phosphatase in the duodenum was detected as three activity bands on SDS-polyacrylamide gel electrophoresis, while in control rats, the enzyme showed a single band. The electrophoretic pattern in hydrocortisone-treated rats was similar to that observed in adult rats. This result supports the view that the maturation of intestinal alkaline phosphatase is primarily regulated by glucocorticoids.
\end{abstract}

In rat small intestine, some enzymes including alkaline phosphatase (AlPase) show drastic changes in their activities during the third week of postnatal development (1). Since these changes are precociously evoked by administration of glucocorticoids and delayed by adrenalectomy. they may be mediated by adrenal corticosteroids. This possibility is also supported by the result that the level of corticosterone in rat plasma rises prior to the change in the activity of enzymes (2). In rat duodenum, the activity of AlPase increases suddenly at about 20 days after birth (3). In a preceding paper. Tojyo (4) demonstrated that the abrupt rise in the activity of AlPase is correlated with the change in electrophoretic pattern which is probably due to the molecular conversion of this enzyme. It is therefore of interest to elucidate whether administration of glucocorticoids to suckling rats precociously produces the molecular conversion of intestinal AlPase. The present study was performed to address this question.

Wistar-strain suckling rats were divided into 4 groups. Each group was subcutaneously injected with the following

\footnotetext{
* Present address: Department of Pharmacology. Higashi-Nippon-Gakuen University School of Dentistry. Ishikari-Tobetsu. Hakkaido 061-02. Japan
}

reagents: hydrocortisone acetate (10 or $50 \mathrm{mg} / \mathrm{kg} /$ day. Merck), aldosterone (1 mg/ $\mathrm{kg} /$ day. Merck). testosterone propionate (50 $\mathrm{mg} / \mathrm{kg} /$ day. Fluka) or saline. These dosages were chosen by reference to previous studies (5-7) where the effect of the steroid hormones on intestinal maturation was examined. Since the intestinal epithelium is strongly responsive to exogenous hydrocortisone in the latter half of the suckling period (8), administrations were carried out at 12 and 13 days after birth. All animals were killed by bleeding under ether anaesthesia when they were 15 days old, corressponding to about a week before the weaning period. The proximal two-thirds of the whole small intestine was quickly removed as the region from the duodenum to the proximal ileum. cleaned of adhering tissue and cut into 12 segments of approximately $2 \mathrm{~cm}$ in length. Each segment was rinsed with cold saline and homogenized in $2 \mathrm{ml}$ of $10 \mathrm{mM}$ Tris- $\mathrm{HCl}$ buffer, $\mathrm{pH}$ 7.4, containing $2 \mathrm{mM} \mathrm{MgCl}_{2}$. Enzyme assay and SDS-polyacrylamide gel electrophoresis were carried out as described previously by Tojyo (4). After electrophoresis, AlPase activity was visualized on the gel by coupling the $\alpha$-naphthol produced from $\alpha$-naphtyl phosphate with Fast violet $B$ salt (9). Protein was determined by the method of Lowry et al. (10). Adult rats, weighing about $300 \mathrm{~g}$, were sacrificed to 

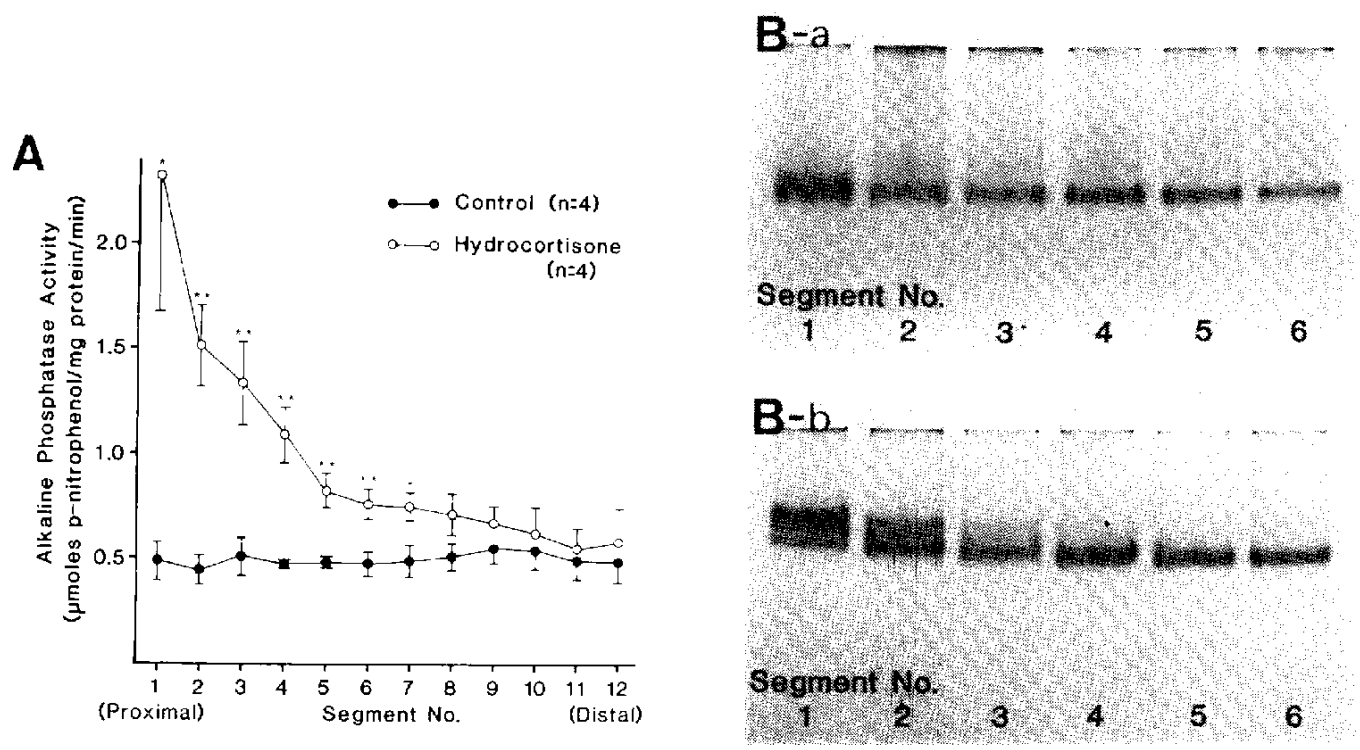

Fig. 1. Effect of hydrocortisone on AlPase in suckling rat smali intestine. The animals were subcutaneously injected with the steroid $(50 \mathrm{mg} / \mathrm{kg} / \mathrm{day})$ or saline at 12 and 13 davs after birth and killed at 15 days. (A) distribution of AlPase activity from the duodenum to the proxima! ileum. Vertical bars represent the S.D. *P<0.02, * P<0.001, compared with the control group. (B) SDS-polyacrylamide gel electrophoretic pattern of AlPase from the 1 st to the 6 th segment. a control group, $b$ : hydrocortisonetreated group. The enzyme in the following segments showed a similar single band in both groups (not shown).

confirm the distribution of AlPase activity and the electrophoretic pattern after weaning. The proximal two-thirds of the small intestine was cut into 24 segments of approximately $3 \mathrm{~cm}$ in length. Enzyme assay and electrophoresis were carried out in the same manner as in the case of suckling rats.

The distribution of AlPase activity along the length of the small intestine was studied in the suckling rats (Fig. 1A). In the controls, there was no significant difference in the activity of AlPase from the duodenum to the ileum. Administration of hydrocortisone (50 $\mathrm{mg} / \mathrm{kg} /$ day) produced a region-dependent increase in the activity of intestinal AlPase. The highest activity was found in the duodenum and the lowest activity in the ileum. A similar result was also obtained at the lower dosage of $10 \mathrm{mg} / \mathrm{kg} / \mathrm{day}$ (not shown). This distribution pattern produced by administration of hydrocortisone was essentially identical with the regional variation in the activity of intestinal AlPase in adult rats as shown in Fig. 2A. When aldosterone or testosterone was administrated to suckling rats, both hormones had no effect on the activity of intestinal AlPase. Figure $1 \mathrm{~B}$ shows the electrophoretic pattern of AIPase from the 1 st to the 6 th intestinal segment in the suckling rats. In the control group (Fig. 1 B-a). AlPase in all segments was detected as a single band with identical mobility on SDSgel electrophoresis. When hydrocortisone was administrated, the electrophoretic pattern of AlPase showed drastic changes. As shown in Fig. 1B-b, three activity bands were observed in the duodenal segments, but a single band in the following segments. This regional variation in the electrophoretic pattern was essentially identical with that of intestinal AlPase in adult rat as shown in Fig. 2B. Unlike hydrocortisone, administration of aldosterone or testosterone to suckling rats had no effect on the electrophoretic pattern of intestinal AlPase.

In this study, we have demonstrated that glucocorticoids precociously evoke the molecular conversion of duodenal AlPase 

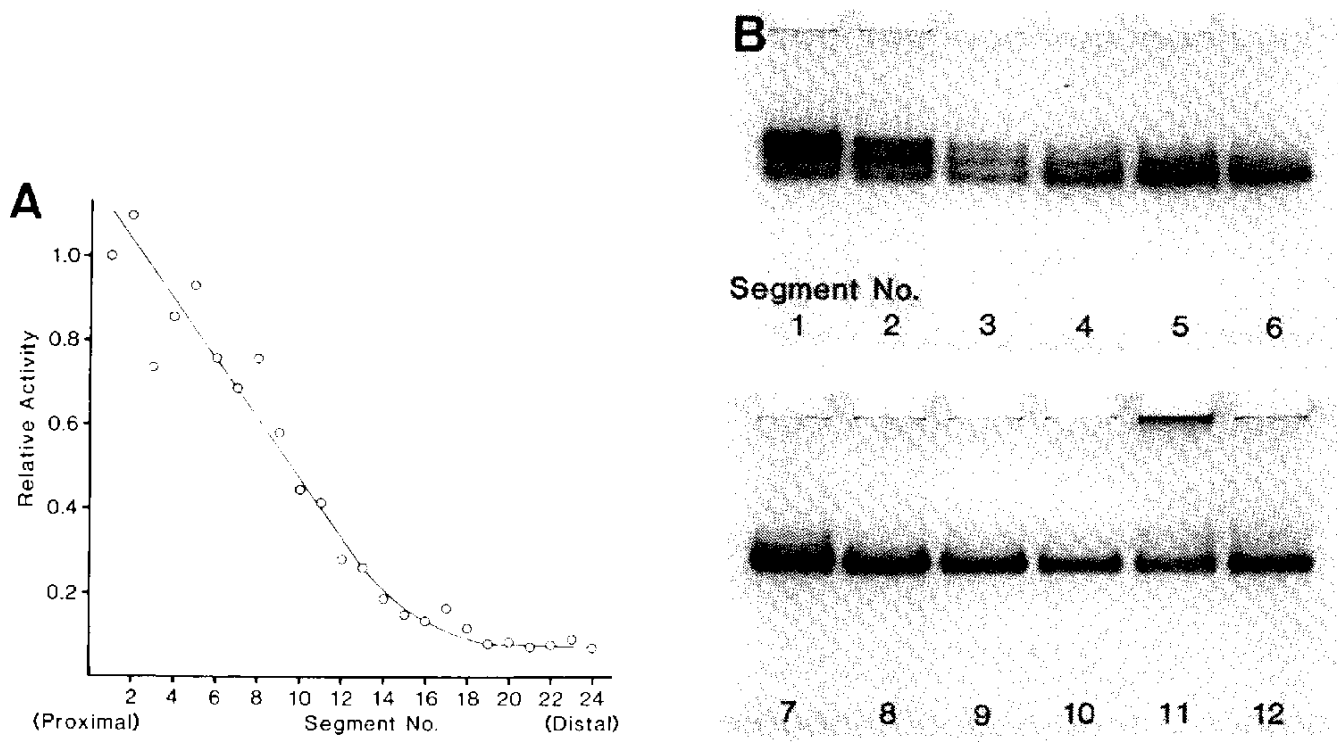

Fig. 2. AlPase in adult rat small intestine. (A) distribution of AlPase activity from the duodenum to the proximal iejunum. A typical resuit of three animals is shown here. Each point represents the value relative to the activity in the 1 st segment. (B) SDS-polyacrylamide gel electrophoretic pattern of AIPase from the 1 st to the 12 th segment.

accompanied with an increase in the activity. This supports the view that the maturation of intestinal AIPase is primarily regulated by glucocorticoids, although it cannot be excluded that other unknown factors may be also involved in it. The physiological significance for the molecular conversion of intestinal AlPase is still unclear. However. since this conversion occurs just before the weaning period, it may be related to adaptation to eating solid food.

\section{References}

1 Henning, S.J.: Postnatal development: coordination of feeding, digestion, and metabolism. Am. J. Physiol. 241, G199-G214 (1981)

2 Henning, S.J.: Plasma concentrations of total and free corticosterone during development in the rat. Am. J. Physiol. 235, E451-E456 (1978)

3 Moog, F. and Yeh, K.-Y.: Intestinal alkaline phosphatase of the rat: Development and distribution of activity with phenylphosphate and $\beta$-glycerophosphate. Comp. Biochem. Physiol. 44B, 657-666 (1973)

4 Tojyo, Y.: Developmental changeover in rat duodenal alka ine phosphatase. Comp. Biochem.
Physiol. 77B, $437-441$ (1984)

5 Halliday, R.: The effect of steroid hormones on the absorption of antibody by the young rat. $J$. Endocrinol. 18, 56-66 (1959)

6 Doell, R.G. and Kretchmer, N.: Intestinal invertase: Precocious development of activity after injection of hydrocortisone. Science 143 , 42-44 (1964)

7 Yeh, K.-Y. and Moog, F.: Development of the small intestine in the hypophysectomized rat. II. Influence of cortisone, thyroxine. growth hormone. and prolactin. Dev. Biol. 47, 173-184 (1975)

8 Moog, F.: The functional differentiation of the small intestine. III. The influence of the pituitaryadrenal system on the differentiation of phosphatase in the duodenum of the suckling mouse. J. Exp. Zool. 124, 329-346 (1953)

9 Tojyo. Y., Saida, K, and Suzuki, A.: Polyacrylamide gel electrophoresis of the alkaline phosphatase of rat dental pulp. Arch. Oral Biol. 26, 1099-1.100 (1981)

10 Lowry, O.H., Rosebrough, N.J., Farr, A.L. and Randall, R.J.: Protein measurement with the Folin phenol reagent. J. Biol. Chem. 193, 265$275(1951)$ 